in May 2005. They replace the 1969 regulations, which only pertained to 3 diseases (cholera, plague and yellow fever) and did little to protect global health security during disease outbreaks, such as SARS, and disasters, such as Chernobyl. According to WHO, the new regulations are much broader and "cover existing, new and re-emerging diseases, including emergencies caused by non-infectious disease agents." The aim is to ensure global health security by a collective response to local problems.

WHO Communications Adviser Gregory Härtl told $C M A J$ that the new regulations "cover any event that has a potential to constitute a public health emergency of international concern, and so include, for example, chemical events and/or foodborne events, which cause a public health risk that may be trans-border."

Under the new regulations, member states must respond to the WHO's request for verification of information, irrespective of its source or origins. Member states are required to immediately assess their core capabilities, and strengthen the pertinent parts so that they can detect, diagnose, notify and adopt appropriate control and prevention measures. Member states must also designate airports, seaports and ground crossings, where diseases can enter or exit a country.

"With well-known international criteria now available for the identification and assessment of international public health threats, and the new requirement for national surveillance and response systems, the implementation of [the regulations] will make the world more transparent and better prepared to respond to public health threats, including the prevention of undue restrictions on travel or trade," Härtl says.

"Given the emergence of infectious diseases like SARS, these regulations are substantially significant," says Bikram Saha, assistant professor of medicine, Midnapore Medical College and Hospital, West Bengal, India. "However, the regulations should be implemented properly," he told CMAJ. — Sanjit Bagchi MD, Kolkata, India

DOI:I0.1503/cmaj.071072

\section{Libya negotiates deal for}

\section{release of doctor, 5 nurses}

A fter 8 years of imprisonment, torture and maltreatment in Libya for allegedly infecting more than 400 children with HIV, purportedly in collusion with the CIA and Israeli secret service, 5 Bulgarian nurses and a Palestinian-born doctor were released on July 24 . The 6 have repeatedly denied the charges.

Libya has been internationally criticized for its disregard for scientific evidence, human rights and due process. As early as 2003, published molecular and epidemiological analyses provided compelling scientific evidence that exonerated the 6 . Results of 2 international reports, filed respectively by the $\mathrm{WHO}$ and a scientific duo hired by the Libyan government itself - including Luc Montagnier, the co-discoverer of HIV - confirmed that the outbreak was nosocomial.

Loath to acknowledge a home-

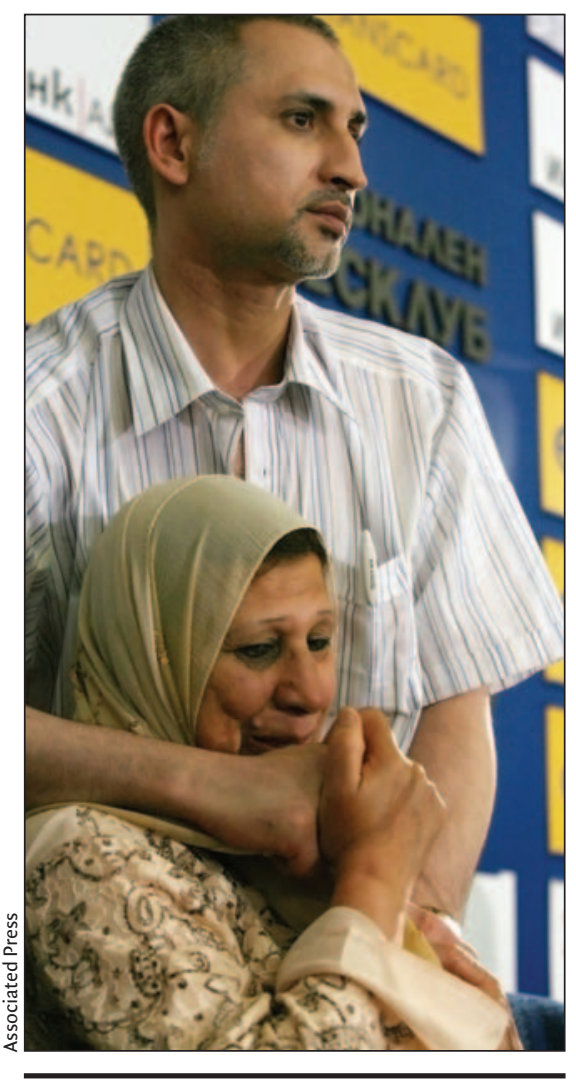

Palestinian-born Bulgarian doctor Ashraf al-Hazouz hugs his mother at a news conference in Sofia, Bulgaria. grown AIDS epidemic that continues to spread due to poor hygiene practices and crumbling infrastructure, Libyan leaders have been accused in editorials in leading journals of using the foreign workers as scapegoats.

The physician and nurses were ultimately released by Libyan leader Colonel Muammar el-Qaddafi on the basis of a 1984 accord between Bulgaria and Libya, which stipulates that citizens of one country convicted of crimes in the other can serve their sentences in their own nation. Cécilia Sarkozy, the wife of France's president, is said to have played a crucial diplomatic role in negotiating the release, thereby clinching a 3-year diplomatic process initiated by the European Union and taken forward by Tony Blair, the former British prime minister.

After their release, the 6 went to Sofia, Bulgaria, where they were promptly pardoned by President Georgi Parvan.

The release came with a price tag. The European Union promised medical support and US $\$ 426$ million for the families of the infected children. The Union has also offered Libya trade agreements, scholarships and visas for travelling in Europe. France has expressed its intention to forge new economic ties with Libya, including helping to build superhighways and trains and develop new civil engineering, aerospace and defense projects.

The seemingly cushy terms of this overdue release have sparked criticism. Susannah Sirkin, deputy director of the Boston-based Physicians for Human Rights has pointed out that "the lives of these nurses and medic were literally ransomed for $\$ 400$ million."

Responding further to Libya's refusal to acknowledge concrete scientific and medical evidence during its trial of the health workers, Sirkin stated, "If this is not addressed, it will have a chilling effect on the willingness of people to enter the health professions and serve in areas where health care needs are great. And the health care in Libya will be no safer than it was when the children were infected." Tavé van Zyl, CMAJ

DOI:Io.I503/cmaj.071075 